\title{
Correction to: Bottom-up effects of endophytic Beauveria bassiana on multitrophic interactions between the cotton aphid, Aphis gossypii, and its natural enemies in melon
}

\author{
N. González-Mas ${ }^{1} \cdot$ M. Cuenca-Medina ${ }^{1}$ ·F. Gutiérrez-Sánchez ${ }^{1} \cdot$ E. Quesada-Moraga ${ }^{1}$
}

Published online: 29 August 2019

○) Springer-Verlag GmbH Germany, part of Springer Nature 2019

\section{Correction to: Journal of Pest Science (2019) 92:1271-1281 https://doi.org/10.1007/s10340-019-01098-5}

In the original publication of the article, the authors have inadvertently made a mistake in the last paragraph in the introduction page 1272 when referring to the systematic position of the generalist predator Chrysoperla carnea, indicating that the order is Coleoptera instead of Neuroptera. The corrected version is given below.

Specifically, we used the endophytic Beauveria bassiana isolate $\mathrm{EABb} 01 / 33$-Su along with the most widespread and important natural enemies of the cotton aphid, Aphis gossypii (Hemiptera; Aphididae), i.e. the generalist predator
Chrysoperla carnea (Neuroptera; Chrysopidae) and the braconid parasitoid Aphidius colemani (Hymenoptera; Braconidae).

Publisher's Note Springer Nature remains neutral with regard to jurisdictional claims in published maps and institutional affiliations.

The original article can be found online at https://doi.org/10.1007/ s10340-019-01098-5.

E. Quesada-Moraga

cr2qumoe@uco.es

1 Departamento de Ciencias y Recursos Agrícolas y Forestales, ETSIAM, Universidad de Córdoba, Campus Rabanales, Edificio C4 Celestino Mutis, 14071 Córdoba, Spain 